\title{
Values for tissue magnesium as a guide in detecting magnesium deficiency
}

\author{
P. LIM, E. JACOB, S. DONG, AND O. T. KHOO \\ From the Department of Clinical Medicine, University of Singapore, and \\ the Department of Pathology, Outram Road General Hospital, Singapore
}

SYNOPSIS A large-scale survey of the normal magnesium content of various human tissues was carried out to facilitate clinical detection of magnesium deficiency, especially occult deficiency.

A review of the literature favours the magnesium content of skeletal muscle as the most reliable index of the body's store of magnesium.

There is a significant difference $(P<0.001)$ in both the serum and erythrocyte magnesium levels between normal pregnant women in the third trimester and the average normal population. The reason for this difference is discussed.

The importance of magnesium in metabolic processes has been adequately emphasized (Wacker and Vallee, 1958), and the clinical aspects of magnesium deficiency have become increasingly recognized with the introduction of rapid, accurate, and precise methods of measuring serum magnesium, especially the method of atomic absorption spectrophotometry (Dawson and Heaton, 1961). Magnesium, however, is a major intracellular cation, the ratio of intracellular to extracellular concentration being 20 to 1 (Gamble, 1954). But as serum levels may not accurately reflect the state of depletion or otherwise of magnesium (Fourman and Morgan, 1962), estimation of the intracellular magnesium content appears to be the answer. The erythrocyte has the advantage of being easy of access, and Wallach, Cahill, Rogan, and Jones (1962) found a low erythrocyte magnesium content in clinical situations associated with magnesium deficiency. However, the erythrocyte magnesium content is approximately only a sixth of that of other cells (though it is still three times that in plasma) and the erythrocyte is different in many important respects from other cells, for example, its lack of a nucleus and relatively short life span.

MacIntyre and Davidsson (1958), feeding rats on a magnesium-deficient diet, observed a highly significant correlation between the length of time during which rats were fed on the diet and their skeletal muscle magnesium content, suggesting a similar correlation between the latter and the extent

Received for publication 15 October 1968. of magnesium depletion. These authors expressed the results of their muscle estimation in milliequivalents of magnesium per kilogram of dry, fat-free solids. Since the amount of magnesium extracellularly is negligible compared with that intracellularly in any muscle specinien (using the values of Gamble, 1954) muscle estimation is essentially a measure of intracellular magnesium. MacIntyre, Hanna, Booth, and Read (1961), using muscle analysis, were able to detect intracellular magnesium depletion in two patients with chronic renal insufficiency not associated with hypomagnesaemia. They also confirmed, with the same method, the presence of magnesium depletion in one case of malabsorption syndrome associated with hypomagnesaemia.

We present in this paper the result of a survey of the muscle magnesium content in normal subjects, which will serve as a guide in the detection of magnesium deficiency states in patients. Other helpful criteria, such as serum and erythrocyte levels, were also estimated both for normal subjects and for normal pregnant women. Fresh postmortem specimens of skeletal muscle, heart, and kidney were analysed in an attempt to establish normal antemortem values for these tissues.

\section{MATERIALS}

Skeletal muscle specimens, about $0.5 \mathrm{~g}$ each, were obtained from consenting patients, undergoing surgery for simple uncomplicated conditions, for example, straight- 
forward appendicitis, herniorrhaphy, and orthopaedic operations. There was no selection with respect to age and sex, the age range being 20 to 60 years. The presence of the slightest evidence of any systemic illness precluded inclusion in this survey. Specimens were obtained from various muscles. MacIntyre et al (1961) showed that the site of origin of skeletal muscle specimens does not matter significantly.

Serum and erythrocyte estimations were made on healthy volunteers of both sexes (with some preponderance of males) ranging from 18 to 60 years of age. Specimens from normal pregnant women were obtained in the third trimester. Blood samples were drawn at any convenient time of the day and therefore from patients who were not fasting. Wallach et al (1962) found no significant difference in plasma and erythrocyte magnesium between blood taken in the fasting state and that taken after breakfast.

Postmortem specimens were taken from road traffic accident cases. Bodies usually arrived at the mortuary within one hour of death and were kept in cold storage. Necropsies were done within 24 hours. Specimens of skeletal muscle, heart, and kidney were obtained during the necropsies only in the absence of any incidental pathology of note. There was no selection with respect to age and sex but as expected the series did show a preponderance of males.

\section{METHODS}

SERUM OR PLASMA Serum or plasma, $\mathbf{0 . 2} \mathrm{ml}$, was added to $5 \mathrm{ml}$ of $0.75 \%$ EDTA and the mixture analysed for magnesium using the atomic absorption spectrophoto meter (Unicam SP 90) with the wavelength set at 2852 $\AA$ and a standard curve previously prepared ranging from $0.2 \mathrm{ppm}$ (parts per million) to $1.2 \mathrm{ppm}$ of $\mathrm{Mg}$ in $0.75 \%$ EDTA solution.

SKELETAL MUSCLE, HEART, AND KIDNEY The specimens (about $0.5 \mathrm{~g}$ each) were dried for 24 hours at $100^{\circ} \mathrm{C}$. These were then ground to a fine powder and washed with an ether : alcohol $(1: 1)$ mixture to remove fat. After drying for a further two hours at $100^{\circ} \mathrm{C}, 10$ to $30 \mathrm{mg}$ samples were incinerated at $450^{\circ}$ for eight hours. The residue was dissolved in $0.75 \%$ EDTA solution and the magnesium content estimated by atomic absorption spectroscopy (Unicam SP 90).

ERYTHROCYTE To $0.1 \mathrm{ml}$ of heparinized whole blood was added a pinch of saponin and $5 \mathrm{ml}$ of $0.75 \%$ EDTA solution. After standing for $\mathbf{3 0}$ minutes, the solution was centrifuged and the supernatant assayed for magnesium by atomic absorption spectroscopy (Unicam SP 90). The PCV and plasma magnesium were estimated and the erythrocyte magnesium is computed as follows:

Erythrocyte magnesium (mg/100 ml erythrocyte)

$$
=\left\{A-\left[B-\frac{(100-C)}{100}\right]\right\} \frac{100}{C}
$$

where $A=M g$ in whole blood $(\mathrm{mg} / 100 \mathrm{ml})$

$$
\mathrm{B}=\mathrm{Mg} \text { in plasma }(\mathrm{mg} / 100 \mathrm{ml})
$$$$
\mathrm{C}=\operatorname{PCV}(\%)
$$

\section{RESULTS}

NORMAL SKELETAL MUSCLE Thirty specimens were analysed. The results are depicted in Figure 1. The mean obtained is $70.8 \mathrm{~m}$-equiv/ $\mathrm{kg}$ dry, fat-free solidsీ with SD of $5 \cdot 7$ (observed range: 60 to $86 \cdot 3$ ).

SERUM AND ERYTHROCYTE In normal subjects, with 87 specimens, the average value for serum was ${ }^{\text {s }}$ $2.0 \pm 0.17$ (SD) $\mathrm{mg} / 100 \mathrm{ml}$; observed range, 1.56 to $\overrightarrow{0}$ $2 \cdot 29$ (Fig. 2). The value for erythrocyte (56 speci- $\overrightarrow{-}$ mens) was $6.3 \pm 0.98$ (SD) $\mathrm{mg} / 100 \mathrm{ml}$; observed range: $4 \cdot 50$ to $8 \cdot 30$ (Fig. 3 ).

For normal pregnant women in the third trimester, the value for serum (105 specimens) was $1.72 \pm 0.05$ ? (SD) $\mathrm{mg} / 100 \mathrm{ml}$; observed range: 1.53 to $2.08 \%$ (Fig. 4). The value for erythrocytes (104 specimens) $\vec{V}$ was $5.29 \pm 0.5(\mathrm{SD}) \mathrm{mg} / 100 \mathrm{ml}$; observed range:을 $4 \cdot 1$ to $6 \cdot 79$ (Fig. 5.)

There is a significant difference $(P<0.001)$ between the serum value for normal subjects and $\overline{\bar{c}}$ that for the normal pregnant women. A significant $\vec{\omega}$ difference of similar degree also exists between erythrocyte values of normal and those of normal pregnant women.

POSTMORTEM SKELETAL MUSCLE Forty-five post-

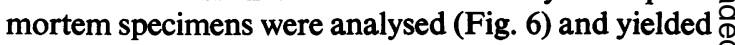
a mean of $72 \cdot 3 \mathrm{~m}$-equiv/ $\mathrm{kg}$ dry, fat-free solids with SD of $6 \cdot 3$ (observed range: $61 \cdot 0$ to $87 \cdot 0$ ). There is no윽 significant difference statistically between this value and that of antemortem skeletal muscle specimens.

POSTMORTEM HEART AND KIDNEY Forty-two post-官 mortem specimens of the heart and 14 of the kidney were analysed with the following results:

Heart 75.6 (SD 8.1) m-equiv/kg dry, fat-free 8 solids: observed range: 60.0 to 88.3 .

Kidney 56.4 (SD 9.3) m-equiv $/ \mathrm{kg}$ dry, fat-free 윽 solids; observed range: $40 \cdot 8$ to $75 \cdot 4$.

\section{DISCUSSION}

Studies with ${ }^{28} \mathrm{Mg}$ (MacIntyre, Davidsson, and $\stackrel{N}{N}$ Leong, 1958) showed a reasonably rapid exchange $\omega$ between muscle magnesium and plasma magnesium, while the exchange between bone magnesium and 0 plasma magnesium was markedly slow by comparison. MacIntyre and his colleagues concluded that muscle magnesium, which constitutes about $20 \%$ of $\frac{T}{T}$ total body magnesium (Forbes, Mitchell, and Cooper, $\frac{\bar{D}}{\mathbb{}}$ 1956), is a readily accessible reservoir that buffers $\frac{\cap}{\Phi}$ any loss of magnesium from the body, while bone $\Omega$ magnesium was relatively inaccessible. MacIntyre et al (1961) further showed that in the presence of $\delta$ 


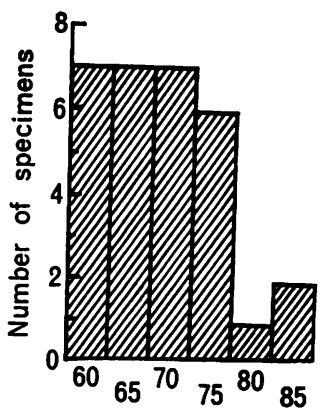

Dry fat-free solids

FIG. 1. (mEq/kg.)

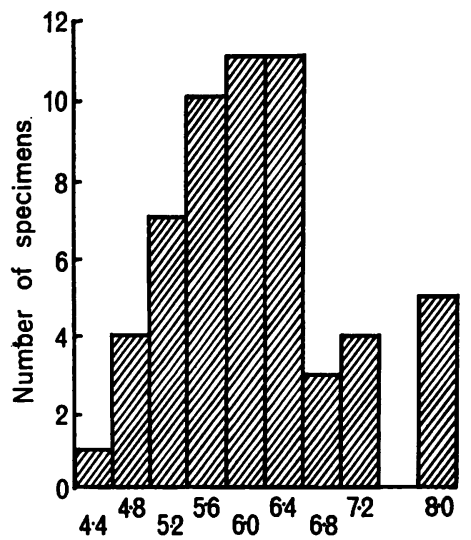

FIG. 3.

Erythrocyte magnesium

(mg. $/ 100 \mathrm{ml}$.)

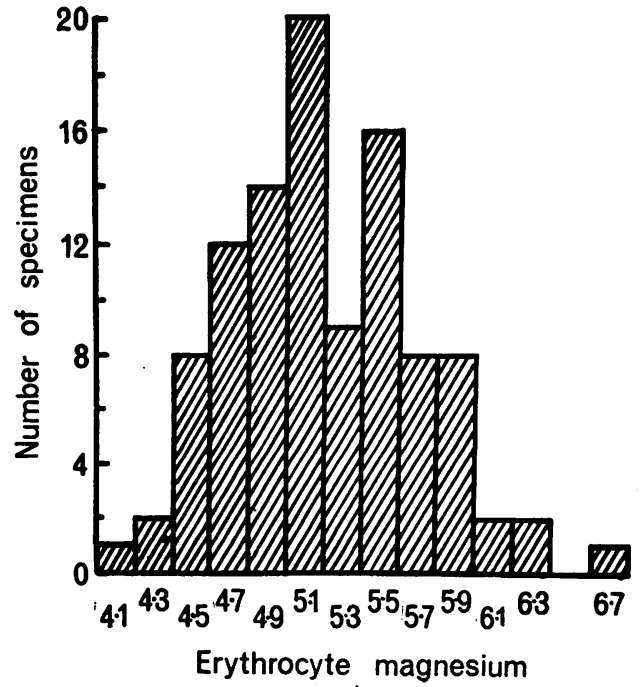

FIG. 5 .

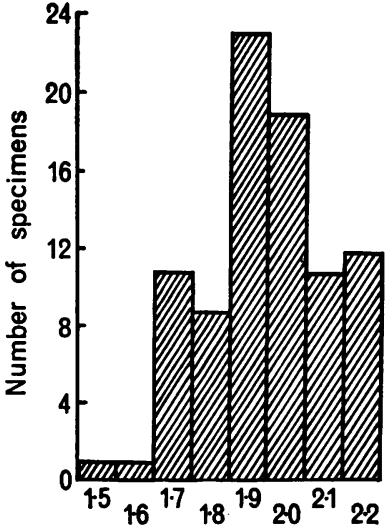

FIG. 2. Șerum magnesium (mg. $/ 100 \mathrm{ml}$ )

FIG. 4 .
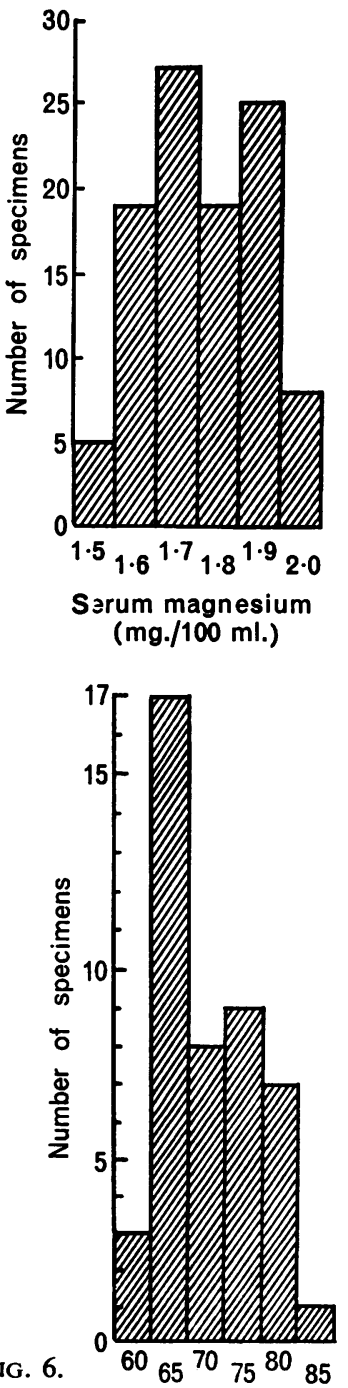

FIG. 1. Analysis of specimens of normal skeletal muscle.

FIG. 2. Serum magnesium assay in normal subjects.

FIG. 3. Erythrocyte values in normal subjects.

FIG. 4. Serum magnesium assay in normal pregnant women in the third trimester.

FIG. 5. Erythrocyte values in normal pregnant women in the third trimester.

FIG. 6. Analysis of postmortem skeletal muscle specimens. 
magnesium depletion, muscle magnesium content was low while bone magnesium was not affected. However, in the rat (MacIntyre and Davidsson, 1958) both muscle and bone magnesium levels fell with magnesium depletion. Dunn and Walser (1966) caused magnesium depletion by dietary means in two subjects and found the muscle magnesium content to be normal, and concluded that the source of lost magnesium must have been bone. These workers, however, did not estimate the magnesium content of bone itself. Watchorn and McCance (1937) found in magnesium-depleted rats little or no change in magnesium content of the tissues other than bone, teeth, and serum, but this was not confirmed by other workers (Tufts and Greenberg, 1938).

It is probable that both muscle and bone magnesium are available reservoirs, with the difference that while the initial brunt of any loss is borne mainly by muscle, in view of the rapid exchange between muscle magnesium and plasma magnesium, bone magnesium provides the second line of defence by virtue of its slower exchange with plasma magnesium. But as bone magnesium constitutes about $66 \%$ of total body magnesium (Forbes et al, 1956) it would prove to be an important reservoir in any state of severe prolonged depletion. The relative ease of obtaining muscle specimens and the relative sensitivity of muscle magnesium to change in magnesium status should make estimations of muscle magnesium a convenient and reliable method of detecting magnesium deficiency.

Since in a man of $70 \mathrm{~kg}$, about 1,000 m-equiv of magnesium is found inside cells and only about $25 \mathrm{~m}$-equiv in the extracellular fluid (Widdowson, McCance, and Spray, 1951) it is clear that the estimation of muscle magnesium is essentially one of intracellular magnesium. Darrow, Harrison, and Taffel (1939) and Cotlove, Holliday, Schwartz, and Wallace (1951) believed that electrolyte analyses were less variable when expressed in terms of dry, fat-free solids. Their method was adopted here. It is interesting that the mean value, calculated from the data of other workers (Wilson 1955; Barnes, Gordon, and Cope 1957), who analysed undried muscle, was $16.7 \mathrm{~m}$-equiv $\mathrm{Mg}$ and $792 \mathrm{~g} \mathrm{H}_{2} \mathrm{O}$ per $\mathrm{kg}$ of fresh muscle. This works out to be about $80 \mathrm{~m}$ equiv/kg dry, fat-free solids, a figure reasonably close to, though somewhat higher than, our value and those of MacIntyre et al (1961). Dickerson and Widdowson (1960) obtained, in babies of from 4 to 7 months old, $20 \mathrm{mg} \mathrm{Mg}$ and $785 \mathrm{~g} \mathrm{H}_{2} \mathrm{O}$ per $\mathrm{kg}$ fresh muscle. This is equivalent to $94 \mathrm{~m}$-equiv $\mathrm{Mg} / \mathrm{kg}$ dry, fat-free solids. Clearly, intracellular magnesium content varies with age, and our data presented in this paper are not applicable to babies and probably not $\frac{\stackrel{0}{5}}{0}$ to children.

The finding that the autolysis that occurred before $\overrightarrow{\vec{F}}$ necropsy did not significantly alter the muscle magnesium content is worth noting. It means that a retrospective diagnosis of occult magnesium de- $\frac{\bar{O}}{\bar{N}}$ ficiency can be made and may help to establish the $\underset{\mathbb{}}{\vec{D}}$ cause of death in difficult cases, especially when $\varrho$ death was associated with convulsions or cardiac $\infty$ arrhythmias of unestablished aetiology. Our value $\overrightarrow{0}$ for postmortem heart specimens, $75.6 \pm 8.1$ (SD) $\mathrm{m}$-equiv/kg dry, fat-free solids, is in very close agree- $\vec{\omega}$ ment with the value of Widdowson and Dickerson (1960) whose average values for two specimens, after correcting for the water content of fresh myocar- N dium, was $76.5 \mathrm{~m}$-equiv $/ \mathrm{kg}$ dry, fat-free solids.

The value for four postmortem specimens $\vec{v}$ of kidney (Widdowson and Dickerson, 1960) after 0 correcting for water content was 43.2 m-equiv $/ \mathrm{kg}$ dry, fat-free solids. Our postmortem kidney $\bar{c}$ result was $56.4 \mathrm{~m}$-equiv/kg dry, fat-free solids. This disparity is difficult to explain. It may be related $\vec{\varphi}$ in some way to the higher intake and greater gastro- $\mathscr{\odot}$ intestinal absorption of magnesium among Orientals. (Seelig, 1964) and the resultant greater turnover of the cation.

Our significantly lower serum values for normal pregnant women in the third trimester is in agree-

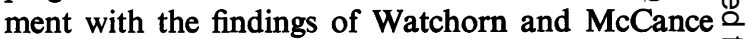
(1932), Carvalho and Daptary (1959), and Wallach $\vec{\circ}$ et al (1962). The first authors also found that a 3 higher proportion of magnesium was ultrafiltrable. The figure of $2.0 \pm 0.17$ (SD) $\mathrm{mg} / 100 \mathrm{ml}$ which we obtained from normal subjects (non-pregnant) agrees well with that of other workers (Elkinton and Danowski, 1955; Herring, Leavell, Paixao, and Yoe, 3 . 1960) who obtained an average value of $2.0 \mathrm{mg} / 100$ $\mathrm{ml}$. These workers demonstrated, in addition, the 3 absence of significant change in serum level from 0 the age of 5 years right up to 90 years.

Our figure, 6.30 ( $\pm 0.98 \mathrm{SD}) \mathrm{mg} / 100 \mathrm{ml}$ for $\frac{}{2}$ erythrocyte magnesium, is in very close agreement with that of Wallach et al (1962), $5 \cdot 3 \pm 0.53$ (SD) $\mathrm{m}$-equiv $/ \mathrm{l}(=6.37 \pm 0.64(\mathrm{SD}) \mathrm{mg} / 100 \mathrm{ml})$. The value $\mathrm{N}$ for normal pregnant women in the third trimester, $\underset{\omega}{ }$ as with serum, was significantly lower than that of the normal population. The importance of this difference in practice cannot be overemphasized. $\frac{\text { C }}{\Phi}$ Overdiagnosis of magnesium deficiency could arise. These lowered values are probably associated with 0 general fluid retention, although the possibility of $\overrightarrow{0}$ occult magnesium deficiency has yet to be ruled out $\stackrel{\mathbb{Q}}{\Omega}$ unequivocally, especially in view of the increasing $\overparen{\mathbb{D}}$ demands from the rapidly growing foetus at this $\frac{a}{\sigma}$ stage of pregnancy. Widdowson et al (1951) found 
that a fullterm baby is born, on average, with $0.26 \mathrm{~g}$ (=22 m-equiv) magnesium per kilogram fat-free body tissue. This important question of occult deficiency is at present under investigation.

We thank Dr Lee Kum Tatt for his generous help. We are grateful to those members of the medical staff who assisted in the collection of the specimens.

\section{REFERENCES}

Barnes, B. A., Gordon, E. B., and Cope, O. (1957). J. clin. Invest., $36,1239$.

Carvalho, D., and Daptary, V. G. (1959). Nutr. Abstr. Rev., 29, 1284.

Cotlove, E., Holliday, M. A., Schwartz, R., and Wallace, W. M. (1951). Amer. J. Physiol., 167, 665 .

Darrow, D. C., Harrison, H. E., and Taffel, M. (1939). J. biol. Chem., 130, 487.

Dawson; J. B., and Heaton, F. W. (1961). Biochem. J., 80, 99.

Dickerson, J. W. T., and Widdowson, E. M. (1960). Ibid., 74, 247.

Dunn, M. J., and Walser, M. (1966). Metabolism, 15, 884.
Elkinton, J. R., and Danowski, T. S. (1955). The Body Fluids. Williams and Wilkins. Baltimore.

Forbes, R. M., Mitchell, H. H., and Cooper, A. R. (1956). J. biol. Chem., 223, 969.

Fourman, P., and Morgan, D. B. (1962). Proc. Nutr. Soc., 21, 34.

Gamble, J. L. (1954). Chemical Anatomy, Physiology and Pathology of Extracellular Fluid, 6th ed. Harvard University Press, Cambridge, Mass.

Herring W. B., Leavell B. S., Paixao, L. M., and Yoe, J. H. (1960). Amer. J. clin. Nutr., 8, 846.

MacIntyre, I., and Davidsson, D. (1958). Biochem. J., 70, 456.

- and Leong, P. C. (1958). Abstr. IVth International Congress of Biochemistry, Vienna, Supplement to Int. Abstr. biol. Sci. p. 160 .

- , Hanna, S., Booth, C. C., and Read, A. E. (1961). Clin. Sci. $20,297$.

Seelig, M. S. (1964). Amer. J. clin. Nutr., 14, 342.

Tufts, E. V., and Greenberg, D. M. (1938). J. biol. Chem., 122, 693.

Wacker, W. E. C., and Vallee, B. L. (1958). New Engl. J. Med., 259,431 and 475.

Wallach, S., Cahill, L. N., Rogan. F. H., and Jones, H. L. (1962). J. lab. clin. Med., 59, 195.

Watchorn, E., and McCance, R. A. (1932). Biochem. J., 26, 54.

Warn, (1937). Ibid., 31, 1379.

Widdowson, E. M., and Dickerson, J. W. T. (1960). Ibid., 77, 30.

-, McCance, R. A., and Spray, C. M. (1951). Clin. Sci., 10, 113.

Wilson, A. O. (1955). Brit. J. Surg., 43, 71. 